\title{
O JORNAL IMPRESSO AINDA RESISTE(?): UMA ANÁLISE SOBRE GÊNEROS JORNALÍSTICOS E SUAS TRANSFORMAÇÕES ${ }^{1}$
}

\author{
FRANCIELE LUZIA DE OLIVEIRA ORSATTO (IFPR)²
}

\begin{abstract}
RESUMO: Diante das transformações tecnológicas que marcam a sociedade atual, o jornalismo e a imprensa têm sofrido visíveis modificações ao longo dos últimos anos. Não só a forma de produzir notícias e reportagens se modificou, mas, principalmente, o consumo desses textos também não ocorre da mesma forma, nas mesmas plataformas. Há tempos se discute a possível "morte" do jornalismo impresso nesse cenário, mas o fato é que ainda há publicações impressas circulando. Assim, levanta-se o seguinte questionamento: em que medida o conteúdo jornalístico tem se transformado? Pode-se dizer a valorização da reportagem - em detrimento da notícia factual, de oferta abundante nos meios digitais - tem se mostrado como uma saída para renovação e/ou sobrevivência do jornalismo impresso? Esses questionamentos são o ponto de partida a partir do qual se desenvolve a presente pesquisa, que objetiva investigar as permanências ou transformações nos gêneros jornalísticos de um jornal impresso. Tendo como base teórica o pensamento de autores como Bakhtin (2011), Marcuschi (2008) analisam-se edições do jornal O Paraná, dos anos de 2019 e 2009. Com a comparação das edições, pode-se concluir que a reportagem está mais presente nos exemplares mais atuais, que valorizam o aspecto local e focalizam questões referentes a cenários atuais e preocupantes em vez da abordagem de fatos pontuais.
\end{abstract}

PALAVRAS-CHAVE: Gêneros do discurso. Gêneros jornalísticos. Jornalismo impresso.

ABSTRACT: In face of the technological changes that mark today's society, journalism and the press have undergone visible changes over the last few years. Not only has the way of producing news and reports changed, but, mainly, the consumption of these texts does not occur in the same way, on the same platforms. The possible "death" of print journalism in this scenario has long been discussed, but the fact is that we still observe print publications circulating. Thus, the following question arises: to what extent has journalistic content been transformed? Is it possible to say that the valorization of the report - in detriment of the factual news, of abundant supply in the digital media - has been shown as a way out for the renewal and / or survival of print journalism? These questions are the starting point from which the present research develops, which aims to investigate the permanences or transformations in the journalistic genres of a printed newspaper. Based on the theoretical thinking of authors such as Bakhtin (2011), Marcuschi (2008), we analyze editions of the newspaper $O$ Paraná, from 2019 and 2009. With the comparison of editions, it can be concluded that the report is more present in the most current editions, which value the local aspect and focus on issues related to current and worrying scenarios rather than the factual approach.

KEYWORDS: Genres of discourse. Journalistic genres. Print journalism.

\section{INTRODUÇÃO}

Os gêneros jornalísticos, como quaisquer outros gêneros, são artefatos históricos intimamente ligados ao domínio da atividade humana em que estão inseridos e a partir do qual se originam e são utilizados. Sua organização interna, a forma de estabelecer relações com seus leitores, o estilo de linguagem utilizada e mesmo as características linguísticas que

\footnotetext{
1 Esta publicação apresenta resultados do projeto de pesquisa "Gêneros discursivos: permanências e transformações" desenvolvido no Instituto Federal do Paraná (IFPR) - Campus Cascavel. A pesquisa conta com a contribuição da discente Luiza Mota Vargas, do curso de Técnico em Análises Químicas Integrado ao Ensino Médio.

2 Docente de Português/Inglês do Instituto Federal do Paraná (IFPR) - Campus Cascavel. Doutora em Letras pela Universidade Estadual do Oeste do Paraná (Unioeste). Franciele.orsatto@ifpr.edu.br.

Revista Trama | Volume 16 | Número 37 | Ano 2020 | p. 18-33 | e-ISSN 1981-4674
} 


\section{$=$ TRAMA $=$}

parecem, em uma primeira análise, meramente estruturais estão relacionados às necessidades de interação entre sujeitos que dialogam, numa cadeia interminável de enunciados. Estudar esses gêneros é necessariamente lançar-se a uma reflexão sobre como a sociedade se organiza, o que valoriza e o que despreza, o que julga como "verdade" ou ficção.

Assim, pode-se dizer que examinar os gêneros jornalísticos é um caminho para compreender melhor como o jornalismo tem se estruturado. Tal investigação ganha relevância na medida em que são visíveis, nos últimos anos, as transformações pelas quais esse domínio da atividade humana tem sofrido. Se há não muitos anos a televisão aberta, o jornal impresso e as revistas semanais eram fontes bastante significativas de informação, hoje tais suportes perderam espaço para o que circula digitalmente, numa rapidez admirável. Em outras palavras, os gêneros digitais passaram a fazer parte do dia a dia das pessoas de forma cada vez mais presente, tornando alguns gêneros impressos praticamente dispensáveis: por que escrever uma carta se é possível enviar com muito mais rapidez um e-mail ou, ainda, uma mensagem de Whatsapp? Ou por que ir até a banca, comprar um jornal impresso e ler uma notícia se é possível obter informação acessando um site ou aplicativo de notícias no celular?

É visível que esse processo tem gerado efeitos na forma como o jornal impresso é produzido e consumido. Desde o começo da popularização da Internet, estudiosos da comunicação têm refletido sobre como o jornal impresso sobreviveria nesse novo cenário alguns deles prevendo, inclusive, a possibilidade de sua "morte". Convivendo com as mudanças, o jornal impresso ainda não "morreu" - ao menos não completamente, visto que ainda há publicações impressas circulando. Parece consensual que mudanças ocorreram; mas quais são essas mudanças? É possível investigá-las, mensurá-las de alguma forma e refletir sobre esse processo? Como tais mudanças se mostram quando olhamos para os gêneros discursivos do domínio jornalístico? Estes são os questionamentos a partir dos quais o presente artigo se debruça.

Para tentar respondê-los ou discuti-los, propõe-se, primeiramente, tratar dos principais conceitos teóricos que embasam o trabalho, a saber: gêneros discursivos/textuais, tipos textuais, bem como dialogismo, com base em Bakhtin (2011) e Marcuschi (2008). A seguir, trata-se mais especificamente dos gêneros do domínio jornalístico, detalhando as características da notícia, nota e reportagem, estabelecendo uma relação com a noção de gêneros jornalísticos apresentada por Marques de Melo (1985). Em seguida, apresenta-se a análise de edições do jornal O Paraná, com foco nas matérias de capa, objetivando verificar quais são as permanências e quais são as transformações notadas quando se confrontam publicações com 10 anos de diferença.

\section{GÊNEROS DO DISCURSO: O PONTO DE PARTIDA TEÓRICO}

Para investigar as mudanças que acontecem na utilização dos gêneros do discurso/textuais, é importante, primeiramente, esclarecer o que se compreende por esse conceito, ainda que ele já seja bastante conhecido e estudado no meio acadêmico. Faz-se necessário, também, delimitar à luz de quais teóricos tal discussão se pauta, visto que ao se falar sobre "gêneros jornalísticos", por exemplo, surgem divergências na forma como estes são classificados. Neste trabalho, tomaremos gêneros do discurso - nomenclatura adotada por Bakhtin (2011) - e gêneros textuais - denominação adotada por Marcuschi (2008) - como sinônimos.

Todos os dias, a todos os instantes, o homem, para estabelecer contato com o outro, utiliza gêneros do discurso. Nos mais diversos domínios da atividade humana, lança-se mão de tipos relativamente estáveis de enunciados, que historicamente vão tomando forma. São 


\section{$=$ TRAMA $=$}

exemplos de gênero: a carta, o telefonema, o conto, o romance, a charge, o relato do dia a dia, o provérbio, a notícia etc.

Com o passar do tempo, novos gêneros vão tomando forma e aparecendo naturalmente, geralmente sendo originados de outros gêneros já existentes. Ou seja, os gêneros são completamente flexíveis e dinâmicos, estando em constante mudança; assim, um gênero que hoje tem uma determinada forma, amanhã pode sofrer uma mutação e passar a ter uma forma diferente, podendo seguir sendo o mesmo gênero.

Os gêneros discursivos existem há certamente muito tempo. Desde a pré-história, quando os homens se comunicavam apenas através de grunhidos, os gêneros já eram usados. Entretanto, os gêneros usados naquela época não são os mesmos atualmente. Se compararmos tanto a quantidade quanto a variedade dos tipos de gêneros diferentes em ambas as épocas, certamente encontraremos uma diferença gritante. Mas quais são os fatores que acarretam essa diferença? É difícil especificar todos com exatidão, mas pode-se dizer que um deles é o aumento significativo do uso da tecnologia.

Coloquemos de uma forma prática: a carta é um gênero que existe há muitos anos; com o uso da tecnologia, surgiu o e-mail, que é muito similar a uma carta, mas que, por ter um formato e suporte diferenciados, é considerado um gênero diferente. Outro exemplo é a conversa face a face; com a tecnologia, tomou forma o telefonema. Este surgiu tendo a conversa face a face como referência e, conforme foi sendo utilizado, ganhou especificidades que o constituíram em novo gênero.

Os gêneros do discurso são inúmeros. Acredita-se que alguns gêneros existam e ainda nem tenham sido notados e catalogados, pois se perdem em meio a tanta variedade:

A riqueza e a diversidade dos gêneros do discurso são infinitas porque são inesgotáveis as possibilidades da multiforme atividade humana e porque em cada campo dessa atividade é integral o repertório de gênero do discurso, que cresce e se diferencia à medida que se desenvolve e se complexifica um determinado campo (BAKHTIN, 2011, p. 262).

Tamanha variedade não impossibilita que haja um estudo sistemático dos gêneros. Retomando como se desenvolveram os estudos sobre gêneros desde a Antiguidade - quase sem se levar em conta a questão linguística geral do enunciado, com foco nos gêneros retóricos ou literários - Bakhtin (2011, p. 262) argumenta que "a questão geral dos gêneros discursivos nunca foi verdadeiramente colocada". E é justamente esse ponto que o autor explora, constituindo-se como precursor de uma área produtiva para o desenvolvimento da pesquisa em linguagem e para, posteriormente, pensar o ensino de língua.

Bakhtin (2011) apresenta uma diferenciação importante, em termos teóricos, quanto aos gêneros, esclarecendo o que seriam gêneros primários e gêneros secundários. Os primários se referem a gêneros simples que se formam na comunicação discursiva imediata, sendo espontâneos, sem planejamento; já os secundários são mais complexos, surgindo de forma organizada e exigindo planejamento. Um diálogo cotidiano é um exemplo de gênero primário; no entanto, se a reprodução de um diálogo integrar um romance, perdendo conexão com a realidade imediata, pode-se dizer que este integra um enunciado secundário.

Outro tópico importante que deve ser colocado à tona é a heterogeneidade tipológica dos gêneros. Costuma-se confundir a ideia de "tipo textual" com a de "gênero textual". Enquanto o gênero textual caracteriza um tipo relativamente estável de enunciado com função social, os tipos textuais podem ser definidos como as diferentes sequências linguísticas internas de um texto, caracterizadas pela natureza "técnica" de sua composição. De acordo com Koch (2010), os tipos textuais são classificados em: narrativos, descritivos, argumentativos, 


\section{$=$ TRAMA $=$}

expositivos ou injuntivos. Desse modo, é possível e há muita probabilidade que um mesmo gênero possua mais de um tipo textual. Esse fenômeno leva o nome de heterogeneidade tipológica.

À medida em que utilizam gêneros, seja como leitoras/ouvintes/espectadoras, seja como autoras/produtoras, as pessoas são capazes de mais ou menos prever o que se encontra ou deve se encontrar em um texto, tanto em termos tipológicos quanto em outros aspectos. A compreensão que os indivíduos têm em relação aos gêneros leva o nome de compreensão metagenérica $(\mathrm{KOCH}, 2010)$ - um fator necessário para que um gênero possa existir, já que este só funciona se for efetivamente usado, reconhecido e compreendido enquanto tal por um grupo social.

Outro aspecto importante a se tratar quando se fala de gêneros do discurso é a questão do dialogismo. Para Bakhtin (2011), o discurso é a língua de forma viva e instável, que está constantemente tomando novas formas, novos modelos, novas configurações e afins. De acordo com o autor, qualquer manifestação discursiva é dialógica, porque envolve, necessariamente, no mínimo dois interlocutores. O dialogismo é, portanto, um conceito amplo, que diz respeito não apenas ao diálogo face a face, mas a todo e qualquer tipo de comunicação, seja ela qual for. Não se pode ignorar que produzimos linguagem visando o outro, esperando respostas - audíveis ou silenciosas. Toda compreensão é prenhe de resposta (BAKHTIN, 2011). Quando tomamos a palavra, entramos na cadeia interminável de enunciados, considerando o que já foi dito e tentando antecipar o que está por vir.

\section{OS GÊNEROS JORNALÍSTICOS}

Os gêneros jornalísticos, desde que surgiram, possuem uma grande importância em nossa sociedade, visto que, por meio deles, os indivíduos podem formar uma opinião própria, criticar algo ou alguém e, principalmente, ficarem cientes de fatos sobre os quais não ficariam caso esses gêneros não existissem. Os gêneros jornalísticos permitem haver uma comunicação direta entre os escritores (em geral, jornalistas) e seus leitores.

Até certo ponto da humanidade, as notícias eram espalhadas de boca em boca, o que fazia com que, conforme essas notícias passassem de pessoa por pessoa, fossem ficando cada vez mais diferentes da versão "original". Isso se passou até que apareceu em cena o jornal, um meio que permitia que uma notícia pudesse ser repassada da mesma forma para toda a população. Marques de Melo $(1985 ; 2016)$ divide os gêneros jornalísticos em seis categorias: gêneros informativos, gêneros opinativos, gêneros utilitários, gêneros ilustrativos, propaganda e entretenimento.

Para a presente pesquisa, focalizamos três gêneros informativos: a nota, a notícia e a reportagem. É indispensável que façamos a diferenciação entre notícia e reportagem, que são dois dos gêneros que aparecem com maior frequência no jornal e muitas das vezes são compreendidos como sinônimos, quando na verdade são distintos.

A notícia trata de um acontecimento em especial, do qual acredita-se que a comunidade ainda não tenha ciência, totalmente novo. Pode-se citar como exemplos de acontecimentos que podem virar uma notícia: um acidente de carro, um homicídio, um roubo, etc. Pode-se dizer também, que por ser uma "fonte infinita" - já que a todo momento novos episódios estão acontecendo ao redor do mundo - a notícia é o principal pilar do jornalismo: "As notícias são a matéria prima do jornalismo, pois somente depois de conhecidas ou divulgadas é que os assuntos aos quais se referem podem ser comentados, interpretados e pesquisados, servindo também de motivo para gráficos a charges (ERBOLATO, 2004, p. 49)". 


\section{$=$ TRAMA $=$}

Entretanto, ao fazer a seleção das notícias que serão publicadas, o jornalista precisa selecionar as notícias que despertam o interesse não de uma pequena quantidade de pessoas, e sim do público em geral, para que haja a compra desses jornais e esse mercado jornalístico siga seu curso.

Outro fato interessante é o aspecto político e social da notícia. Ao ser escrita por um determinado jornalista, este pode fazê-lo de várias maneiras, gerando interpretações diferentes. Isso influencia o público, o que nos faz pensar se a notícia não pode vir a ser uma das principais formas de manipulação em massa. Além de ter o poder de manipular como um fato é noticiado, o jornal seleciona o que é conveniente vir a público - e o que é conveniente ser ignorado ou até mesmo censurado -, fazendo com que boa parte da população tenha ciência apenas do que se quer que ela tenha.

Atualmente, a notícia em jornal impresso diário vem correndo imenso perigo, pelo fato de as informações estarem chegando à população muito mais rapidamente através de telejornais e, principalmente, pelos computadores, celulares, tablets, etc. (LAGE, 2003). Consequentemente, questiona-se a permanência do jornal impresso, já que este é predominantemente sustentado pela notícia. Com a possível extinção da notícia nos jornais, o que poderia vir a garantir a permanência do jornal diário seria explorar o gênero reportagem.

A reportagem trata de um tema que já é conhecido superfluamente pela população, mas que será trazido de uma forma mais aprofundada, para que seja analisado, criticado, etc. Diferentemente da notícia, a reportagem não trata de um acontecimento em especial em um determinado momento, mas se relaciona ao ato de discorrer sobre um assunto (seja ele político, social, cultural, econômico, entretenimento) de forma explícita e detalhada. Pode-se citar como exemplo de possíveis temas de reportagem: feminismo, número de homicídios no Brasil etc.

Outro gênero que é importante que se tenha conhecimento é a nota. A nota é um texto curto, que retrata brevemente um acontecimento, com um formato mais objetivo que a notícia.

Conforme Lage (2003), comparada à notícia, a reportagem tem como particularidade o fato de poder versar sobre qualquer tópico, podendo ser direcionada a um determinado grupo de pessoas, como adolescentes, mulheres, hippies, geeks, etc. Possuindo um leque de possibilidades muito maior que o da notícia, a reportagem exige uma pesquisa mais aprofundada e cautelosa, podendo vir a mudar o pensamento do leitor dependendo da forma com que for apresentada.

Esses três gêneros - nota, notícia e reportagem -, bastantes presentes no jornalismo impresso, também podem ser vistos nos suportes digitais. Com o aumento significativo do uso de tecnologias, é bastante provável que o contato com esses gêneros aconteça, hoje, mais nos suportes digitais do que nos impressos. Não se pode negar que a tecnologia faz parte de nossa rotina atualmente; passamos a usar celulares, computadores, tablets etc. para fazer o que anteriormente fazíamos sem estes aparelhos, pelo simples fato de que com eles se torna mais fácil e rápido executar determinadas tarefas.

A agilidade e a praticidade proporcionadas pela tecnologia têm levado as pessoas a não verem mais necessidade de comprar o jornal em forma física, já que notícias, reportagens ou notas podem ser encontradas em sites, blogs, aplicativos de veículos noticiosos etc. Basta acessar um dispositivo digital para ficar informado sobre o que está acontecendo ao redor do mundo sem precisar sair de casa - ou estando em trânsito para qualquer lugar.

Esse cenário levou à diminuição da vendagem dos jornais físicos e fez com que muitos veículos deixassem de existir, ao menos na versão impressa. No Brasil, em apenas 6 anos, 8 jornais pararam de circular, conforme aponta Pacete (2015). Apesar de serem grande importância e influência no país, mesmo assim foram extintos. São eles: Gazeta Mercantil referência para o jornalismo econômico brasileiro, que circulava desde 1920 - em 2009; Jornal 


\section{$=$ TRAMA $=$}

do Brasil, um dos mais antigos do país, em 2010; O Estado do Paraná, em 2011 - dando lugar ao Paraná Online (atualmente, redirecionado para https://www.tribunapr.com.br/); Jornal da Tarde, jornal diário de São Paulo, em 2012; Diário do Comércio, de São Paulo, e O Sul, de circulação na zona metropolitana de Porto Alegre, em 2014; Brasil Econômico, em 2015. Podese notar que esses jornais começaram a sair de circulação em 2009, ano em que a Internet começava a ser usada com mais frequência pelos brasileiros, pois estava se tornando de mais fácil acesso. Alguns desses jornais, que saíram de circulação física, ainda possuem site, blog ou página na internet, o que indica uma mudança importante na forma como o conteúdo jornalístico tem sido consumido.

\section{OS GÊNEROS NO JORNAL IMPRESSO: MUDANÇAS E PERMANÊNCIAS}

Tendo explicitado a base teórica e discutido os principais conceitos de que lançaremos mão, é possível, agora, olhar para o objeto de estudo que se propõe analisar, a saber, edições do jornal impresso O Paraná, que circula em Cascavel (PR) e região. Segundo informações disponibilizadas em seu site , o veículo foi fundado em 15 de maio de 1976 e circula hoje com mais de 30 mil exemplares, alcançando 66 municípios em sua versão impressa. O mesmo grupo é também responsável pelo periódico Hoje News Cascavel, de mais de 40 anos de tradição, e Tribuna Hoje News, com sede na cidade de Umuruama (PR). O site do veículo disponibiliza conteúdo atualizado diariamente, de acesso gratuito; assinantes também podem ter acesso à versão impressa integral digitalizada.

Para realizar a análise proposta, foram selecionadas quatro edições de abril de 2009 (12/04, 13/04, 14/04 e 15/04) e quatro edições de abril de 2019 (16/04, 17/04, 18/04 e 20 e 21/04). As edições não tem 10 anos exatos de diferença entre elas, devido a uma limitação de disponibilidade do corpus; de qualquer forma, este não parece um fato determinante para a reflexão que se propõe a fazer, visto que tais edições foram publicadas no mesmo período do ano, próximo à Pascoa.

A edição mais antiga selecionada, de 12/04/2009, domingo de Páscoa, é organizada a partir dos seguintes cadernos: Política, Brasil, Mundo, Economia, Caio Gottlieb (Coluna de opinião), Opinião, Última Hora, Cidades, Policial, Esportes e Variedades. Essa edição tem como manchete: "Cadeia é bomba-relógio em contagem regressiva", a qual se refere a texto publicado no caderno Policial. A manchete é acompanhada de foto e de um parágrafo oferecendo, verbalmente, mais detalhes. Há, também, na capa: 3 chamadas de matérias acompanhadas de foto; 3 chamadas apenas com elementos verbais; 1 reprodução da charge publicada no caderno Opinião. Na parte superior, ao lado esquerdo do logotipo com o nome do jornal, encontra-se uma tabela com cotações do dólar e, ao lado direito, um pequeno anúncio publicitário.

Uma análise mais atenta da manchete e do texto a que ela faz referência permitem observar alguns aspectos importantes no sentido de identificar se se trata de uma notícia ou de uma reportagem. Tendo em vista que a notícia informa a respeito de um fato pontual, pode-se dizer não encontramos resposta para a pergunta "o que aconteceu?" quando examinamos a manchete "Cadeia é bomba-relógio em contagem regressiva". Não há verbo de ação sendo utilizado, como é comum na notícia, mas há um verbo de ligação que indica permanência: a cadeia não "está", mas "é" uma bomba-relógio. Assim, sugere-se que o problema tematizado, embora atual, não é novo: a cadeia não se transformou recentemente em uma bomba-relógio; ela apresenta em sua essência, em seu "ser", essa característica.

A matéria ocupa toda uma página do caderno policial, contendo um texto principal e um texto secundário, e os elementos verbais são acompanhados de 4 fotos: uma de um 


\section{$=$ TRAMA $=$}

entrevistado, duas retratando a superlotação do presídio e uma mostrando corpos estirados ao chão em chacina ocorrida no ano anterior à publicação da matéria.

O texto se inicia sem seguir à estrutura do lead ${ }^{3}$, permitindo ao leitor entender melhor porque a cadeia é adjetivada, no título, como bomba-relógio:

Guaíra - Considerada a cidade mais violenta do Sul do País proporcionalmente à sua população, Guaíra tem uma cadeia pública que se parece muito mais do que um barril de pólvora prestes a explodir: o presídio localizado no centro da cidade, próximo ao rio Paraná, na divisa com o Paraguai, lembra mais uma bomba-relógio em franca contagem regressiva (PRESÍDIO, 2009, p. B7).

No parágrafo seguinte, é possível identificar que o texto foi originado a partir de um fato pontual: a mudança de delegado da cidade de Guaíra: "Esse é um dos problemas que está se deparando (sic) o novo delegado da cidade, José Aparecido Jacovos, 45 anos, que substituiu o colega Pedro Lucena, transferido para Rolândia". Apesar de haver um fato pontual, que acabou de acontecer, sendo relatado, este fato não é o foco do texto; não se informa ao leitor simplesmente que "Guaíra tem novo delegado", como seria possível prever se se tratasse de uma notícia. Em vez disso, o texto aborda o desafio central com o qual o novo delegado terá de lidar: a superlotação da cadeia que já foi palco, inclusive, de chacina que resultou na morte de 15 pessoas no ano anterior.

A abordagem a respeito desse acontecimento anterior é feita em trecho subintitulado "Chacina foi exceção e autores seriam psicopatas". A separação do texto em subtítulos, recuperando fato anterior que permite compreender melhor o cenário atual indica que houve uma apuração mais cuidadosa para a escrita de um texto com mais aprofundamento. Em suma, todas essas características permitem concluir que o texto se enquadra no gênero reportagem.

A edição de 13/04/2009 (segunda-feira), é organizada a partir dos mesmos cadernos da edição dominical, com exceção da coluna de Caio Gotlieb. A capa traz duas chamadas de matérias do caderno Variedades; duas chamadas de Esportes; duas chamadas do caderno Policial; uma do caderno Brasil; uma sobre Política; duas referentes ao caderno Opinião. A manchete é a seguinte: "Oeste fatura $\mathrm{R} \$ 431$ milhões anuais com a produção de leite". O texto correspondente à manchete se encontra no caderno "Cidades" e ocupa pouco mais de meia página, dividindo espaço com duas notícias ("Oeste fará conferências regionais de agricultura" e "Mulher assume a Acimacar") e uma foto-legenda ("Secretaria da Saúde recebe van e carro zero quilômetros").

A matéria em questão, composta de elementos verbais e de uma foto de vacas leiteiras, traz um título um pouco diferente da manchete presente na capa: "Cadeia do leite gira $R \$ 431,5$ mi na região Oeste". Ao analisar o primeiro parágrafo, é possível compreender como o dado citado foi obtido:

Toledo - A região Oeste possui uma das maiores bacias leiteiras do Paraná, notabilizada pelo volume de produtividade. O mais recente relatório anunciado pelo Deral (Departamento de Economia Rural) da Seab (Secretaria Estadual de Agricultura e Abastecimento), com base em números levantados em 2007, revelam uma produção anual de 863 milhões, 755 mil e 710 litros de leite. Calculando com os valores do preço do litro de leite pago ao produtor, estimado em $\mathrm{R} \$ 0,50$, a atividade garante uma movimentação econômica na região de $\mathrm{R} \$ 431,5$ milhões (CADEIA, 2009, p. B4).

\footnotetext{
${ }^{3}$ Em jornalismo, o lead (ou lide) é o primeiro parágrafo de uma notícia, que fornece as informações básicas sobre o fato noticiado. Em geral, apresenta as respostas para as perguntas "O quê? Quem? Quando? Onde? Como? Por quê?.
}

Revista Trama | Volume 16 | Número 37 | Ano 2020 | p. 18-33 | e-ISSN 1981-4674 


\section{$=$ TRAMA $=$}

Pode-se dizer, a partir da leitura desse parágrafo, que o fato que deu origem ao texto é o anúncio do relatório revelando dados da produção de leite levantados em 2007. É possível, identificar, nesse trecho, elementos que, estruturalmente, responderiam a algumas das perguntas básicas do lead. O agente da ação (quem?) seria "O mais recente relatório anunciado pelo Deral (Departamento de Economia Rural) da Seab (Secretaria Estadual de Agricultura e Abastecimento)". O fato noticiado (o que?), seria "revelam uma produção anual de 863 milhões, 755 mil e 710 litros de leite". Quanto à resposta para "quando?", esta não se apresenta explicitamente, mas pode-se inferir que seja "recentemente", já que não seria interessante divulgar dados de um relatório antigo e/ou já conhecido. Em relação a "onde?", também não há elemento explícito, mas infere-se que o anúncio tenha sido realizado no Paraná. Na verdade, o local do anúncio do relatório pouco importa, visto que o importante é o que seus dados revelam sobre o Oeste paranaense. O "como" e o "por quê?" o anúncio revela seus dados não aparecem explicitamente porque não parece relevante explorar "como" o anúncio foi feito (por exemplo: efusivamente, em uma reunião etc.) e nem "por quê" (por exemplo: porque alguma autoridade/entidade solicitou etc.) A partir do fato central (anúncio revela dados sobre produção leiteira), focaliza-se desdobramentos do que esses dados apontam; explora-se que houve um "acréscimo de produção em relação a 2006", que o "Oeste é detentor da maior bacia leiteira do Estado", compara-se a produção do Oeste com a da região de Castro (que é maior considerando a produção por vaca) etc.

Ainda que haja um fato pontual sendo noticiado neste texto e que seu primeiro parágrafo pareça atender mais ou menos à estrutura do lead, sua extensão (há um texto principal e dois textos secundários, identificados por subtítulos), bem como o aprofundamento do texto parecem apontar para uma aproximação maior com o gênero reportagem do que com o gênero notícia. Há diversos dados que são apresentados, além da notícia "nua e crua" do que revelou o relatório em questão. Além disso, destaca-se que diversas fontes são consultadas: uma técnica do Deral de Cascavel, o presidente da Rural Leite, um consultor de produção de leite e um produtor de leite que atua há dez anos no setor. Assim, pode-se dizer que essa matéria se caracteriza como exemplar do gênero reportagem.

A edição de 14/04/2009 (terça-feira), é organizada a partir dos mesmos cadernos de dias de semana e tem como manchete: "Socorro aos municípios cobre só 1/3 das perdas". Na capa, observa-se, além da manchete acompanhada de uma foto e um parágrafo de texto verbal: três chamadas com fotos, sete chamadas com apenas texto verbal, um anúncio publicitário pequeno na parte superior, ao lado direito da logomarca do jornal, e uma tabela com cotação do dólar, ao lado esquerdo.

Internamente, a matéria central aparece com um título um pouco diferente: "Pacote do governo compensa apenas um terço das perdas", é composta apenas por elementos verbais (ou seja, não há nenhuma foto ou ilustração) e ocupa em torno de meia página, ao lado de três notícias; na mesma página, há, ainda, um anúncio publicitário pequeno e dois gêneros que chamam a atenção: um infográfico com a previsão do tempo e uma tabela com os resultados da loteria. Esses gêneros, aliás, não "sumiram" do jornal: também aparecem em todas as edições recentes analisadas, de 2019.

O texto se inicia relatando o fato principal que justifica sua existência:

Brasília - O ministro do Planejamento, Paulo Bernardo, anunciou ontem que o governo vai enviar ao Congresso Nacional uma Medida Provisória (MP) que visa a recomposição do Fundo de Participação dos Municípios (FPM) às prefeituras. Segundo o ministro, todos os municípios serão atendidos (PACOTE, 2009, p. A12). 


\section{$=$ TRAMA $=$}

Pode-se identificar, neste parágrafo, os seguintes elementos do lead: quem? "O ministro do Planejamento, Paulo Bernardo"; o que? "anunciou que o governo vai enviar ao Congresso uma Medida Provisória [...]"; quando? "ontem"; onde? em Brasília. "Como" e "por quê" o anúncio foi feito não está explícito neste parágrafo. Mas, nos parágrafos seguintes, explora-se os pormenores do fato, procurando explicar o que esse anúncio representa. Como fontes, são consultados o ministro do Planejamento, Paulo Bernardo, e o ministro de Relações Institucionais, José Múcio Monteiro. Ao longo do texto, são apresentadas citações diretas e indiretas dessas fontes.

A extensão do texto em análise é relativamente breve, visto que há 9 parágrafos. Apesar de haver certa exploração dos pormenores do fato, observa-se que esta é centrada, basicamente, no anúncio público das duas autoridades em questão. Não parece ter havido, portanto, uma apuração mais detalhada, que originasse um aprofundamento maior, digno de uma reportagem. O fato de o texto ter sido publicado no caderno "Última hora" também é significativo nesse sentido: informa-se o que ocorreu (o anúncio) e procura-se explicar sua importância e seus desdobramentos a partir do anúncio em si, sem parecer ter havido uma pesquisa mais detalhada, justamente pelo fato ser de "última hora", ou seja, ter acabado de acontecer. Essas características - ser centrado em um fato pontual, "quente", ter extensão breve, mencionar poucas fontes e seguir a estrutura do lead e da pirâmide invertida - permitem afirmar que se trata, portanto, de uma notícia.

A edição de 15/04/2009 (quarta-feira), é organizada a partir dos mesmos cadernos de dias de semana e tem como manchete: "Lula atribui ao pânico $50 \%$ da culpa pela crise". A manchete é acompanhada de uma fotografia e de um pequeno parágrafo, o que parece ser um padrão na diagramação, já que o mesmo ocorre com as outras capas de 2009 observadas. Assim como a edição do dia anterior, a capa conta com uma tabela com a cotação do dólar e um pequeno anúncio publicitário ao lado da logomarca do jornal. Há, além da manchete, duas chamadas com texto verbal e imagem e sete chamadas apenas com texto verbal.

Na parte interna, o texto referente à manchete é intitulado da seguinte forma: "Para Lula, 50\% da crise mundial 'é um pouco de pânico'" e chama a atenção por sua extensão breve: é composto por apenas seis parágrafos e acompanhado de uma fotografia. A matéria ocupa pouco mais de um quarto da página e divide espaço com duas notícias, uma nota e três anúncios publicitários. O primeiro parágrafo é centrado no acontecimento pontual que deu origem à matéria:

Telêmaco Borga - Ao falar sobre a economia mundial ontem em Telêmaco Borba, durante evento dos 110 anos da Klabin, o presidente Luiz Inácio Lula da Silva afirmou que o Brasil vive momento de "estabilidade e credibilidade política" e que o pessimismo tem grande influência sobre os efeitos da crise (PARA LULA, 2009, p. B7).

Assim como acontece com a manchete do dia anterior, este texto tem como fato central o conteúdo de um anúncio feito por uma autoridade. Enquanto, no dia anterior, tratava-se do que falou o ministro do Planejamento, nesta edição se trata do conteúdo de um anúncio do então presidente, Luiz Inácio Lula da Silva. É possível identificar, em sua abertura, os seguintes elementos do lead: quem? "o presidente Luiz Inácio Lula da Silva"; o que? Afirmou que o Brasil vive momento de "estabilidade e credibilidade política e que o pessimismo tem grande influência sobre os efeitos da crise"; quando? Ontem, "durante evento dos 110 anos da Klabin"; onde: em Telêmaco Borba. O "como" e o "por quê" não aparecem no lead e, aliás, não são muito explorados neste texto. 


\section{$=$ TRAMA $=$}

Os parágrafos seguintes são dedicados a relatar o que foi dito por Lula, com a predominância do discurso direto. Dos cinco parágrafos, dois são inteiramente compostos por falas de Lula entre aspas e os outros mesclam o discurso direto com a paráfrase, com pouca ou nenhuma interferência e/ou análise do jornalista que escreve ou acréscimo de informações além do que o presidente diz, como se pode ver no terceiro parágrafo:

Vivemos um momento de estabilidade e credibilidade política. Não há venda barata de otimismo", disse Lula, ao ressaltar que o Brasil está melhor do que outros países em relação aos problema da economia mundial. Na cerimônia da Klabin, ao lado do governador em exercício, Orlando Pessuti, ele voltou a dizer que a crise "pode ser muito mais passageira do que se imagina (PARA LULA, 2009, p. B7).

Por se centrado em um fato pontual - o anúncio de Lula - sem mergulhar em seus desdobramentos; por ter como base a utilização de apenas uma fonte - o próprio Lula; por ter extensão breve e por seguir a estrutura do lead e pirâmide invertida, pode-se dizer que o texto em questão classifica-se como uma notícia.

Analisando-se as edições atuais, de 2019, observa-se uma mudança relevante quanto ao número de cadernos, a quantidade de páginas do jornal e o tamanho da página - antes, o formato para impressão era o standard (600x670mm); em 2019, usa-se o formato tabloide (280x430mm). A edição de 16/04/2019 (terça-feira) é organizada a partir dos seguintes cadernos: Política, Geral, Economia, Oeste, Variedades, Esportes e Classificados, ou seja, quatro cadernos a menos que as edições de 2009. Ao todo, a edição possui apenas 20 páginas e tem como manchete: "'Estão matando pessoas por vaidade', acusa secretário."

Internamente, a matéria aparece com o título "Consamu Oeste - UPAs lotadas e mensagem indicam boicote a Cascavel" e ocupa três quartos da página, dividindo espaço com um anúncio publicitário. O fato motivador que deu origem ao texto é a acusação feita pelo secretária de Saúde de Cascavel ao presidente do Consamu, como se pode notar no primeiro parágrafo:

Cascavel - Os quase 50 pacientes que esperam nas UPAs (Unidades de ProntoAtendimento) por leitos de hospital e uma mensagem enviada pelo secretário de Saúde de Cascavel, Rubens Griep, ao presidente do Consamu (Consórcio Intermunicipal Samu Oeste) e prefeito de Palotina, Jucenir Stentzler, acusando-o de matar pessoas por vaidade e destruir o trabalho realizado pelo Consórcio em Cascavel, sinalizam um possível boicote do Consamu à cidade (CONSAMU, 2019, p. 9).

Embora o ponto de partida seja um acontecimento pontual - a acusação do secretário - observa-se que a abordagem adotada para a produção do texto vai além de simplesmente noticiar essa acusação. Leva-se em conta, conjuntamente, a situação das UPAs na cidade e há uma apuração mais cuidadosa que resulta num aprofundamento do material escrito. Uma diversidade de fontes são consultadas para a produção do texto: o secretário de saúde, um vereador, o prefeito, o presidente do Consamu (que não respondeu às mensagens e ligações do jornal) e o diretor técnico do referido consórcio. Com exceção da fonte que não atendeu à reportagem, observa-se depoimentos de todas as outras fontes, reproduzidos via discurso direto no texto.

Quanto à escrita do primeiro parágrafo, nota-se que este não segue exatamente a estrutura do lead. É possível identificar, estruturalmente, "quem" (os quase 50 pacientes que esperam nas UPAs [...] por leitos de hospital e uma mensagem enviada pelo secretário de Saúde de Cascavel [...]) e "o que" (sinalizam um possível boicote do Consamu à cidade); "onde" e "quando" estão implícitos: em Cascavel, recentemente; "como" e "por que" não são 


\section{$=$ TRAMA $=$}

identificados neste trecho. Porém, nota-se que este parágrafo não apresenta elementos do lead de forma meramente informativa; há uma notável interpretação do jornalista que escreve, que, após toda a coleta de informações, conclui, reflexivamente, o que está ocorrendo. Nesse sentido, observa-se uma valorização da interpretação muito mais do que da informação em si.

Há, também, outra particularidade que chama a atenção. Os elementos verbais que compõem o texto são acompanhados de uma fotografia e de uma reprodução de conversa ocorrida pelo aplicativo Whatsapp, na qual se observa a acusação que deu origem à matéria. Neste "print", observa-se, inclusive, o uso de palavrões e de sinais de pontuação indicando a informalidade do texto e a ênfase no caráter emocional com que ele foi escrito: "Por pura vaidade destruiu tudo!!! Deus é maior do que sua prepotência!!! Vai se f...!!! [...]"

Interessante observar o hibridismo com relação à composição deste texto, que o caracteriza como um gênero secundário: a fotografia, os elementos verbais organizados em parágrafos e o "print" da mensagem de Whatsapp compõem um todo ao qual é possível referir-se como uma reportagem. Tal mescla não poderia ocorrer em 2009, visto que o uso do Whatsapp de forma ampla é mais recente. Pode-se observar, então, que os gêneros não funcionam independentemente; um gênero como a conversa de Whatsapp, ao ser incorporado pelo gênero reportagem, acaba gerando mudança neste gênero: a reportagem de 2019 não tem exatamente os mesmos elementos de 2009, visto que as mudanças na forma como as pessoas se comunicam acabam transparecendo.

Ao falar sobre como se chega à denominação dos gêneros, Marcuschi (2008) explica que vários critérios são levados em conta, sendo o propósito comunicativo ou função um critério mais importante que os aspectos estruturais - visto que um gênero pode assumir a estrutura de outro ou pode misturar-se com outro:

É bastante comum que nos órgãos de imprensa se usem as contaminações de gêneros ou se proceda à hibridização como forma de chamar mais a atenção e motivar a leitura. De algum modo, parece que essa estratégia tem o poder quase mágico de levar as pessoas a interpretarem muito mais e com mais intensidade 0 que ali está. Esse aspecto mereceria um estudo à parte (MARCUSCHI, 2008, p. 168).

Em suma, pode-se dizer que, como se trata de um texto de maior aprofundamento, em que há um visível foco na interpretação e na consulta de várias fontes de informação, de extensão mais extensa e inclusive englobando outros gêneros (fotografia e conversa de Whatsapp), trata-se de uma reportagem.

A edição seguinte, de 17/04/2019 (quarta-feira), é organizada a partir dos seguintes cadernos: Política, Geral, Economia, Oeste, Variedades, Esporte e Imobiliário. Ao todo, possui 32 páginas e tem como manchete: "Cadeia leiteira trava com a precária rede elétrica." Como é comum nas edições observadas, internamente o texto aparece com título diferente: "Queda de luz vira tormento à pecuária". O primeiro parágrafo do texto apresenta o seguinte:

Cascavel - Produtores de leite da região oeste têm um sério inimigo que pesa nas finanças, e não é o preço pago pelo produto nem o custo da produção: são as quedas frequentes da energia elétrica, que têm feito com que muitos produtores joguem leite fora por falta de refrigeração. (MANFRIN, 2019a, p. 10)

Ao analisar esse parágrafo, em conjunto com o título, pode-se perceber que o texto é originado não a partir de um fato exatamente pontual, mas de algo que "vem acontecendo", a saber, a queda de luz. Não se trata de algo que aconteceu uma vez, mas de um cenário considerado preocupante. Esse cenário é o ponto de partida para abordar o assunto com maior profundidade e tratar de vários aspectos ligados à produção leiteira. Ocupando quase toda a 


\title{
$=$ TRAMA $=$
}

página - há apenas um anúncio publicitário pequeno, que ocupa aproximadamente 1/6 de todo o espaço - o texto é dividido em subtítulos que tratam do "Planejamento e empreendedorismo", e das boas notícias do setor neste ano, tratadas em "Um ano para respirar aliviado". Além dos elementos verbais, o texto é composto por uma foto mostrando vacas leiteiras.

Há várias fontes consultadas para a elaboração do texto: um casal de produtores de leite, o presidente do POD (Programa Oeste em Desenvolvimento) e um extensionista do Instituto Emater. Além da declaração das fontes, o texto apresenta diversos dados numéricos com relação à produção leiteira, detalhando custos e o preço de venda do litro de leite etc. Pelo aprofundamento que apresenta e pelo fato de tratar de um assunto e não de um fato pontual, o texto em questão pode ser classificado como uma reportagem.

A penúltima edição a ser analisada, de 18/04/2019 (quinta-feira), é organizada a partir dos seguintes cadernos: Política, Geral, Economia, Oeste, Variedades, Esportes e o suplemento Educação. Ao todo, possui 32 páginas ( 24 da edição normal, mais 8 páginas do suplemento) e tem como manchete: "Aeroporto de Cascavel é o pior do Estado e o de Foz é o melhor." Internamente, o texto aparece com o título "Aeroporto de Cascavel é o pior do Paraná", enfatizando-se sua relevância quanto ao aspecto local. Diferentemente do que se observa em outras edições, o texto ocupa toda a página, sem dividir espaço com anúncios publicitários. Além dos elementos verbais, há uma fotografia do aeroporto. O primeiro parágrafo é transcrito a seguir:

\begin{abstract}
Cascavel - Um estudo inédito elaborado pela equipe de apoio do deputado estadual Homero Marchese revelou o que empiricamente já se sabe. O desempenho do Aeroporto Municipal de Cascavel tem sido pior ano após ano. O foco do estudo é a análise da aviação civil comercial nos principais aeroportos do Paraná (Cascavel, Curitiba, Foz do Iguaçu, Londrina e Maringá), de 2014 a 2018, mas traz informações detalhadas de cada um deles desde o ano 2000. O coordenador é o economista Joao Ricardo Tonin (MANFRIN, 2019b, p. 10).
\end{abstract}

Identificando os elementos que compõem este parágrafo, tem-se "quem" - "um estudo inédito elaborado pela equipe de apoio do deputado estadual Homero Marchese" e "o que" "revelou o que empiricamente já se sabe - o desempenho do Aeroporto Municipal de Cascavel tem sido pior ano após ano". Não é possível identificar "onde", mas infere-se que esta é uma informação que pode ser mais ou menos inferida: é provável que o anúncio tenha sido feito no próprio estado do Paraná; além disso, trata-se de algo menos relevante do que o conteúdo do anúncio: importa mais o que foi anunciado e não onde o anúncio ocorreu. Também não é possível identificar "quando" neste parágrafo; porém, no quarto parágrafo do texto, explicita-se que o estudo foi divulgado "nesta semana". Percebe-se, assim, que a informação não foi imediatamente veiculada, isto é, noticiada no dia seguinte ao que se teve conhecimento. É provável que os dados do relatório tenham analisados e divulgados no momento em que o veículo de comunicação julgou pertinente; demorar alguns dias para publicar as informações não invalidou sua relevância para transformá-las em uma reportagem de capa.

A partir disso, nota-se que o texto, embora tenha sido motivado por um fato pontual - o anúncio dos resultados de um estudo sobre os aeroportos do Paraná - não se centra nesse fato, mas procura, partir dele, abordar o assunto, isto é, o cenário preocupante do transporte aéreo em Cascavel. Assim, os dados do estudo são bastante explorados no texto, que, inclusive, é inteiramente destinado a detalhá-los e explicá-los. Optou-se por destinar uma página inteira a essa abordagem detalhada, sem consulta a outras fontes de informação. 


\section{$=$ TRAMA $=$}

Por sua extensão, pelo enfoque na abordagem mais detalhada e interpretativa e por seu caráter não imediatista - como se comentou, aborda-se mais o assunto do que um fato pontual -, pode-se classificar tal texto como uma reportagem.

A última edição analisada, de 20 e 21/04/2019 (sábado e domingo), é organizada a partir dos seguintes cadernos: Política, Geral, Oeste, Variedades, Esportes, Imobiliário e o suplemento Saúde. Ao todo, a edição possui 36 páginas (28 da edição normal, mais 8 do suplemento) e tem como manchete: "Conta que não fecha: Há 7 famílias para cada criança apta à adoção." Internamente, o texto aparece com o título "Há sete pretendentes para cada criança apta à adoção" e ocupa dois terços da página, dividindo espaço com uma coluna de opinião (Coluna Esplanada). Essa coluna não é elaborada pela equipe do próprio jornal; tratase de um material independente que, pelo que se pode inferir, é vendido a veículos de comunicação. A matéria central da edição é composta por uma foto, além dos elementos verbais. O primeiro parágrafo é transcrito a seguir:

Cascavel - Apesar dos avanços, a adoção de crianças ainda é um assunto cheio de tabus e a burocracia tem feito com que centenas (ou até milhares) de crianças e adolescentes cresçam em abrigos à espera de um lar. O problema é que, quanto mais velhas, mais difícil se torna para serem adotadas (MANFRIN, 2019c, p. 7).

Observando o que é exposto nesse parágrafo, não se pode reconhecer elementos do lead que respondam à pergunta: o que aconteceu? O foco do texto não está em noticiar um fato pontual; tanto é que se usa um verbo de ligação: "a adoção de crianças é um assunto cheio de tabus", seguido de uma construção com o particípio, indicando algo processual: "a burocracia tem feito com que centenas (ou até milhares de crianças e adolescentes cresçam em abrigos à espera de um lar". Assim, nota-se o direcionamento do texto no sentido de abordar um assunto atual (a adoção) em vez de noticiar um fato.

Em dez parágrafos, o texto traz dados sobre adoção que demostram um cenário preocupante: apesar de haver pretendentes a adotar crianças e adolescentes, os processos de adoção não tem acontecido com a rapidez com que deveriam. Para explorar a questão, são trazidos ao texto dados do Conselho Nacional de Justiça e do Cadastro Nacional de Adoção, além de informações levantadas pela jornalista Ana Davini, autora do livro "Te amo até a lua", que versa sobre o tema. Percebe-se, portanto, uma abordagem além do imediatismo, do factual; isto, aliado ao aprofundamento do texto e à sua extensão, permitem classificá-lo como uma reportagem.

Comparando-se os exemplares do corpus, é possível observar mudanças que sugerem transformações no jornal O Paraná que ocorreram ao longo dos 10 anos que separaram as edições. Para facilitar a visualização dessas mudanças, o quadro abaixo reúne as informações levantadas na análise e já comentadas ao longo do texto:

\begin{tabular}{|l|l|l|l|l|l|}
\hline Ano & Título & Gênero & Local & $\begin{array}{l}\text { Estrutura } \\
\text { do } 1^{\circ} \\
\text { parágrafo }\end{array}$ & $\begin{array}{l}\text { Elemento motivador do } \\
\text { texto }\end{array}$ \\
\hline 2009 & $\begin{array}{l}\text { Cadeia é bomba-relógio } \\
\text { em contagem regressiva }\end{array}$ & Reportagem & Guaíra & Sem lead & $\begin{array}{l}\text { Fato pontual: nomeação } \\
\text { de novo delegado }\end{array}$ \\
\hline 2009 & $\begin{array}{l}\text { Oeste fatura } R \$ 431 \\
\text { milhões anuais com a } \\
\text { produção de leite }\end{array}$ & Reportagem & Toledo & Com lead & $\begin{array}{l}\text { Fato pontual: anúncio de } \\
\text { relatório com dados } \\
\text { sobre produção de leite }\end{array}$ \\
\hline 2009 & $\begin{array}{l}\text { Socorro aos municípios } \\
\text { cobre só } 1 / 3 \text { das perdas }\end{array}$ & Notícia & Brasília & Com lead & $\begin{array}{l}\text { Fato pontual: anúncio do } \\
\text { ministro do } \\
\text { Planejamento }\end{array}$ \\
\hline 2009 & $\begin{array}{l}\text { Lula atribui ao pânico } \\
50 \% \text { da culpa pela crise }\end{array}$ & Notícia & $\begin{array}{l}\text { Telêmaco } \\
\text { Borba }\end{array}$ & Com lead & $\begin{array}{l}\text { Fato pontual: anúncio do } \\
\text { presidente }\end{array}$ \\
\hline
\end{tabular}

Revista Trama | Volume 16 | Número 37 | Ano 2020 | p. 18-33 | e-ISSN 1981-4674 


\section{$=$ TRAMA $=$}

\begin{tabular}{|c|c|c|c|c|c|}
\hline 2019 & $\begin{array}{l}\text { Estão matando pessoas } \\
\text { por vaidade', acusa } \\
\text { secretário }\end{array}$ & Reportagem & Cascavel & Sem lead & $\begin{array}{l}\text { Fato pontual: acusação } \\
\text { do secretário de Saúde } \\
\text { de Cascavel }\end{array}$ \\
\hline 2019 & $\begin{array}{l}\text { Cadeia leiteira trava com } \\
\text { a precária rede elétrica }\end{array}$ & Reportagem & Cascavel & Sem lead & $\begin{array}{l}\text { Cenário atual/recente } \\
\text { em vez de fato pontual: } \\
\text { quedas de energia; }\end{array}$ \\
\hline 2019 & $\begin{array}{l}\text { Aeroporto de Cascavel é } \\
\text { o pior do Estado e o de } \\
\text { Foz é o melhor }\end{array}$ & Reportagem & Cascavel & Sem lead & $\begin{array}{l}\text { Cenário atual/recente } \\
\text { em vez de fato pontual: } \\
\text { situação do aeroporto } \\
\text { de Cascavel }\end{array}$ \\
\hline 2019 & $\begin{array}{l}\text { Conta que não fecha: Há } \\
7 \text { famílias para cada } \\
\text { criança apta à adoção }\end{array}$ & Reportagem & Cascavel & Sem lead & $\begin{array}{l}\text { Cenário atual/recente } \\
\text { em vez de fato pontual: } \\
\text { dificuldades na adoção } \\
\text { de crianças e } \\
\text { adolescentes }\end{array}$ \\
\hline
\end{tabular}

Como é possível observar, as edições mais recentes demonstram uma valorização do gênero reportagem em detrimento da notícia, que era mais presente nas edições de 2009. Enquanto, em 2009, os fatos pontuais tinham grande relevância, em 2019 o enfoque dos textos se direciona para assuntos de maior amplitude, cenários atuais e preocupantes que merecem ser abordados. Em outras palavras, trata-se de problemas que vem afetando os cascavelenses há um certo tempo e, se nada for feito, continuarão a afetá-los no futuro: problemas na saúde, dificuldade na produção leiteira, complicações no transporte aéreo e entraves na adoção de crianças e adolescentes. Pode-se inferir que, devido ao acesso fácil às notícias por ferramentas digitais, não é mais tão interessante informar ao leitor sobre o que ocorreu ontem: muita coisa acontece entre o momento em que se finaliza a edição do jornal até ela ser impressa e distribuída para então, finalmente, chegar ao leitor. Nesse meio tempo, os acontecimentos impactantes já chegam ao conhecimento do público por outros meios, sejam a TV ou, principalmente, os meios digitais. Não há motivo, então, para noticiar o que o público muito provavelmente já viu em outro lugar. Mas há espaço, ainda, para abordar questões que merecem ser alvo de reflexão, exigindo um aprofundamento maior.

A estruturação do texto, sem seguir o lead, parece uma mera consequência desse enfoque. Se o foco não está em um acontecimento pontual, não parece haver motivo para seguir a essa estrutura e responder às seis perguntas básicas quando o mérito do texto é, justamente, oferecer ao leitor o que está além do "básico". Assim, permite-se um trabalho estilístico maior, mais flexível, sem se atentar a essas regras. Mais importante que ir direto ao ponto, nesse caso, é atrair o leitor de alguma forma - ainda mais diante da concorrência com os meios digitais. O conselho de Ricardo Noblat aos jornalistas segue nesse sentido: "Vocês têm só uma bala na agulha para capturar a atenção dos leitores: as primeira linhas de um texto" (NOBLAT, 2003, p. 100).

Outro ponto que merece ser comentado diz respeito ao local a que os textos se referem e/ou foram produzidos. Enquanto, nas edições de 2009, há diferentes locais sinalizados, as edições de 2019 restringem-se a Cascavel. Mais uma vez, pode-se fazer uma inferência relacionada a como os meios digitais interferem na produção e recepção de notícias. Se, antes, era interessante que o jornal impresso tratasse de acontecimentos distantes geograficamente, agora essa abordagem parece desnecessária. Pode-se pensar que as duas manchetes de 2009 que se referem a fatos de repercussão nacional - "Socorro aos municípios cobre só 1/3 das perdas" e "Lula atribui ao pânico 50\% da culpa pela crise" - provavelmente não seriam escolhidas para edições atuais, visto que já seriam tematizadas em outros veículos de recepção mais imediata que o jornal impresso. A abordagem de temas locais, que mais dificilmente 


\section{$=$ TRAMA $=$}

aparecem nos portais on-line, vem aparecendo como uma espécie de diferencial do jornal impresso. Não se ignora o fato de que atualmente há, também, sites noticiosos destinados a abordar notícias locais. Estes, porém, apostam muito mais no imediatismo da notícia "quente" do que no aprofundamento proporcionado pelas reportagens.

Em resumo, pode-se dizer que três aspectos chamaram a atenção quanto a mudanças observadas nos exemplares do corpus quando comparados: a presença mais marcante do gênero reportagem - e, como consequência, o abandono do estrutura do lead; o enfoque aos acontecimentos locais; e a abordagem de questões referentes a cenários atuais e preocupantes em vez da focalização de fatos pontuais.

\section{CONSIDERAÇÕES FINAIS}

Como foi possível perceber a partir das análises, o jornal impresso sofreu, no período de 10 anos, modificações significativas. Tais modificações fazem parte, na verdade, de um processo em curso, iniciado com a ascensão dos meios digitais. Cada vez mais a notícia está perdendo lugar no jornal impresso porque este se tornou um meio de pouco imediatismo quando comparado a outras formas de se obter informação. Há 10 anos, o jornal impresso não era, obviamente, uma fonte única nem a mais imediata de informação; no entanto, a presença dos meios digitais intensificou sobremaneira a necessidade de o impresso adaptar-se para garantir sua permanência, ao menos por enquanto.

A reportagem está, hoje, mais presente, mas apenas esse fato não é suficiente para dizer que o jornal impresso terá vida longa - visto que a diminuição do número de páginas e de cadernos do veículo analisado, aliado à mudança para um formato de página menor, apontam que, provavelmente, haja dificuldades em custear a produção de um material jornalístico mais robusto, seja ele de caráter informativo ou mais interpretativo.

Observando as edições do corpus, pode-se observar que alguns gêneros deixaram de circular - por exemplo, a cotação do dólar sempre presente nas capas de 2009 - enquanto outros ainda permanecem - a previsão do tempo e o resultado da loteria - algo que, provavelmente, tende a desaparecer, justamente por serem acessíveis em meios mais imediatos. Quanto aos gêneros centrais da análise realizada - a notícia e a reportagem -, devese lembrar, ainda, da incorporação de outros gêneros, como a conversa de Whatsapp. Isto aconteceu em um dos textos observados, deixando à mostra possíveis desdobramentos quanto à renovação dos gêneros notícia e reportagem a serem investigados em um corpus mais extenso.

Lembrando que, como afirma Bakhtin (2011, p. 268), "os enunciados e seus tipos, isto é, os gêneros discursivos, são correias de transmissão entre a história da sociedade e a história da linguagem", é preciso reforçar a importância do estudo dos gêneros. Tendo em vista que notícias e reportagens são gêneros relevantes em nossa sociedade e, por isso, trabalhados no ambiente escolar, examiná-los mais a fundo permite compreender melhor a historicidade que deve ser considerada nesse trabalho. Ainda mais quando alunos nativos digitais, bombardeados pelo que se vende como "informação em tempo real" - às vezes fáceis de serem confundidas com as "fake news" -, desconhecem os "primórdios" dos gêneros jornalísticos em questão. Diante disso, novas possibilidades de reflexão e de pesquisa, portanto, abrem-se à investigação.

BAKHTIN, Mikhail. Estética da criação verbal. 6. ed. São Paulo: WMF Martins Fontes, 2011.

CADEIA do leite gira R\$431,5 mi na região Oeste. O Paraná, Cascavel, ano 33, 13 abril 2009, Cidades, p. B4. 
CONSAMU Oeste - UPAs lotadas e mensagem indicam boicote a Cascavel. O Paraná, Cascavel, ano 43, 16 abril 2019, Economia, p. 9.

ERBOLATO, Mario. Técnicas de codificação em jornalismo. São Paulo: Ática, 2004.

KOCH, Ingedore Villaça. Ler e compreender: os sentidos do texto. 3. ed. São Paulo: Contexto, 2010.

LAGE, Nilson. A estrutura da notícia. São Paulo: Ática, 2003.

MANFRIN, Juliet. Queda de luz vira tormento à pecuária. O Paraná, Cascavel, ano 43, 17 abril 2019a, Oeste, p. 10.

MANFRIN, Juliet. Aeroporto de Cascavel é o pior do Paraná. O Paraná, Cascavel, ano 43, 18 abril 2019b, Oeste, p. 10.

MANFRIN, Juliet. Há sete pretendentes para cada criança apta à adoção. O Paraná, Cascavel, ano 43, 20 e

21 abril 2019c, Oeste, p. 7.

MARCUSCHI, Luiz Antônio. Produção textual, análise de gêneros e compreensão. São Paulo: Parábola

Editorial, 2008.

MARQUES DE MELO, José. A opinião no jornalismo brasileiro. Petrópolis: Vozes, 1985.

MARQUES DE MELO, José. ASSIS, Francisco de. Gêneros e formatos jornalísticos: um modelo classificatório. Intercom - Revistra Brasileira de Ciências da Comunicação. São Paulo, v.39, n.1, p.39-56, jan./abr. 2016. Disponível em: <http://www.scielo.br/pdf/interc/v39n1/1809-5844-interc-39-1-0039.pdf> Acesso em: 7 nov. 2019.

NOBLAT, Ricardo. A arte de fazer um jornal diário. São Paulo: Contexto, 2003.

PACETE, Luiz Gustavo. Brasil perdeu oito jornais em 6 anos. Meio \& Mensagem. 15 jul. 2015. Disponível em: <https://www.meioemensagem.com.br/home/midia/2015/07/15/brasil-perdeu-oito-jornais-em-6-anos.html> Acesso em: 1 ago. 2019.

PACOTE do governo compensa apenas um terço das perdas. O Paraná, Cascavel, ano 33, 14 abril 2009, Última hora, p. A12.

PARA Lula, 50\% da crise mundial é 'um pouco de pânico'. O Paraná, Cascavel, ano 33, 15 abril 2009, Cidades, p. B7.

PRESÍDIO é bomba em contagem regressiva. O Paraná, Cascavel, ano 33, 12 abril 2009, Policial, p. B7. 